\title{
Wool Materials Application History in Kyrgyz Traditional Medicine
}

\author{
Chynykhan Satybaldieva1, Makpuratkhon Sultanova', Abylabek Asankanov', \\ Ainagul Dzhooshbekova ${ }^{3}$, Ainura Tagaibekova1, Aizirek Satybaldieva4, \\ Gulnaz Chynykeeva ${ }^{5}$, Zamira Eshnazarova², Tolgonai Tynybek kyzy1, \\ Madina Nurlan kyzy ${ }^{6}$, Zhypargul Abdullaeva ${ }^{*}$
}

${ }^{1}$ Department of History, Archeology and Ethnography, Osh State University, Osh, Kyrgyzstan

${ }^{2}$ Kyrgyz Republic Academy of Sciences, Institute of history Bishkek, Kyrgyzstan

${ }^{3}$ Department of Kyrgyzstan History and Ethnology, I. Arabaev Kyrgyz State University, Bishkek, Kyrgyzstan

${ }^{4}$ Department of Social Health and Healthcare, International Medical Faculty, Osh State University, Osh, Kyrgyzstan

${ }^{5}$ Department of General History and Teaching Methods, Osh State University, Osh, Kyrgyzstan

${ }^{6}$ Department of Foreign Languages, Osh State University, Osh, Kyrgyzstan

${ }^{7}$ Science and Research Department, Osh State University, Osh, Kyrgyzstan

Email: *jypar.science@oshsu.kg

How to cite this paper: Satybaldieva, C., Sultanova, M., Asankanov, A., Dzhooshbekova, A., Tagaibekova, A., Satybaldieva, A., Chynykeeva, G., Eshnazarova, Z., Tynybek kyzy, T., Nurlan kyzy, M., \& Abdullaeva, Z. (2021). Wool Materials Application History in Kyrgyz Traditional Medicine. Open Journal of Social Sciences, 9, 43-50

https://doi.org/10.4236/jss.2021.96005

Received: May 7, 2021

Accepted: June 6, 2021

Published: June 9, 2021

Copyright $\odot 2021$ by author(s) and Scientific Research Publishing Inc. This work is licensed under the Creative Commons Attribution International License (CC BY 4.0).

http://creativecommons.org/licenses/by/4.0/ (c) (i) Open Access

\begin{abstract}
The relevance of this article is related to the Kyrgyz people's skills in using natural wool for the treatment of various diseases in nomadic life. As a source of natural resources, sheep and goat wool with mineral substances were used. Sheep's wool is the main source of wool in the Kyrgyz people's nomadic life. Sheep wool is also widely used in traditional Kyrgyz medicine. The Kyrgyz people knew from their nomadic experience, and scientists determined that the physical properties and chemical composition of wool had a very positive effect on human health. Theoretical methods were based on the scholarly and scientific article's analysis in historical aspect. Empirical method is a popular and important research method in ethnology, which was implemented through surveys, participation in the process, observations and interviews of informants who are familiar with traditional medicine and wool products' health effects. Research results were obtained using the comparative-historical method through a scientific cycle and a hypothesis. The article describes how the Kyrgyz people were able to work in a variety of ways in nomadic life, as well as promoting good health.
\end{abstract}

\section{Keywords}

Wool Materials, History, Application, Kyrgyz Traditional Medicine, Plants, Animals, Minerals 


\section{Introduction}

The relevance in this article focused on human health and life issues, which are a very important aspect in traditional medicine (TMs) that make use of natural products of great significance (Yuan et al., 2016). According to scientific sources, in the earliest stages of social development, an ancient man began to use natural resources (Kristoffersen et al., 2017) to fight diseases and ailments. Depending on the Kyrgyzstan territory, 95 percent of which is mountainous, farming was dominated by wool production. The main purpose of the study is the historical use of wool in traditional medicine, features of traditional life as a historical and ethnographic source, to reveal ethnocultural information, to determine the benefits of sheep's wool in traditional medicine (Podulova, 2012). Livestock farming including sheep breeding supports the local people livelihoods from nomadic times and took place in the Soviet period; Kyrgyz people are producing sheep's wool characterized by valuable traits as a high adaptation to severe mountain conditions, satisfactory meat and fat qualities, high growth energy, endurance, and resistance to various diseases (Farrington, 2005; Deniskova et al., 2019; Lushikhin, 1964).

Research problems in this work are to reveal traditional life features and historical ethnographic sources, benefits in the use of sheep's wool. Research objectives are historical applications of wool by people in traditional medicine since ancient times.

\section{Research Materials and Methods}

In this article, the authors used theoretical, empirical and comparative-historical methods based on information about applications of wool in traditional Kyrgyz medicine. Author's field materials were collected from specific regions. Theoretical methods in this work are used to analyze other scholars' works and scientific articles related to the subject in historical aspect. The most popular and important research method in ethnology is the empirical method. The empirical method in this article is implemented through surveys, participation in the process, observation and interviews. Author documented ethnological processes taking place during the scientific expedition and received information from informants.

\section{Results and Discussions}

\subsection{Wool Application History}

In the historical development of the Kyrgyz, traditional medicine was widely supplemented with traditional knowledge. It is well known that such knowledge is of particular interest to modern science. In Kyrgyz folk medicine, in addition to herbal remedies, the most widely used are sheep, goats, and night owls. The number of diseases and illnesses that Kyrgyz doctors and physicians treat without resorting to medicinal plants is small.

Natural sheep's wool is a unique natural material that the Kyrgyz have been using for a long time, and there are still no worthy synthetic analogs. Wool is 
one of the first materials used by ancient people to sew clothes and is a natural raw material that provides a comfortable life in the harshest conditions.

Wool is the most complex type of agricultural product. Types and breeds of animals, individual animals, parts of wool, shapes, fiber composition and color, time of haircut, method of preparation for sale and its production technology, are different for sale and processing in the market (Sidortsev et al., 2010).

According to well-known anthropologist E. Taylor's analysis, as human beings evolved physically, so did their culture, and as their knowledge increased, so did the quality of their tools. For example, in the selection process, the runes of human wild ancestors changed the natural properties of domestic sheep in areas necessary for the cultivation of wool, its collection, efficient processing and use (Ratnapalan, 2008).

Archaeologists have unearthed evidence that sheep farming and wool production started in the 4th century B.C. Sheep breeding and wool spinning were well known in ancient Mesopotamia (McMahon, 2020) and Babylon. In ancient Rome (Sabatini et al., 2019), they were already engaged in breeding, resulting in a new merino sheep breed (Ciani et al., 2015) of the Tarintino breed. Gaius Julius Caesar himself supported the crossing and acquisition of new sheep breeds to produce clothing. At the beginning of our era, the Greek poet Ovid described the technology of using sheep's wool. Wool fabrics are practical and relatively inexpensive and can be easily colored in a variety of colors. In England, sheep farming was established on a serious industrial basis, and today the Lord Chancellor of England sits on a woolen sack; currently, sheep, camel, rabbit and goat wool are used.

The amazing properties of wool were known as far back as 7000 years ago in China and ancient Egypt, as wool played an important major role in the nation's development and the discovery of new worlds (Giles, 2009). Wool has been known since the early collective society. The ancient Slavic economy used mainly sheep's wool. Sheep believed to have been domesticated in Asia Minor and Egypt thousands of years ago. A woolen cloth was found on the hills of the Oka River in 1000 B.C.

From the very beginning of human society, animal hair has been one of the most widely used physiotherapeutic remedies in traditional medicine because of its anesthetic, anti-inflammatory and tonic effects. The greatest therapeutic effect is provided by undyed wool. The more fibrous and hard the wool, the higher the energy effect. The Kyrgyz learned this through their life experience. Therefore, natural wool products have been widely used by sick and weak people.

Informants familiar with traditional medicine and livestock that produce wool products reported health effects and use of sheep's wool in traditional medicine. Comparative-historical method is the scientific method, which helps in revealed general and special historical events comparison; allows finding and comparing the studied object development level resulting in changes (Large Soviet Encyclopedia, 2021). 


\subsection{Wool Use in Traditional Kyrgyz Medicine}

According to Kyrgyz traditional medicine, woolen clothes are especially useful for people with kidney and liver diseases (Nookat region filed materials, 2020). Products made from sheep's wool can help to prevent high blood pressure. This is due to the special properties of sheep's skin providing equal pressure on the body and reduces increased moisture and friction. Some methods of treating pathological diseases with the help of sheep and goat wool as well as with animal skin used by ancestors, have been preserved and are still used today. In the Kyrgyzstan southern regions, clothes and household items are made of sheep's wool (Satybaldieva, 2009).

Wool carpets felt (Satybaldieva et al., 2021) and sacks have a great impact on health. Because the wool of sheep, goats, and sheep was the raw material for weaving. It is a very valuable raw material for industry, especially among sheep products, which are distinguished by their high quality physical and technological natural properties. Sheep's wool is thin, long, wrinkle-free, silky, and dyed with various dyes. Its properties allow it to make beautiful garments, knitwear, clean beautiful carpets and other products that have quality (Dzhetigenov \& Nurgaziev, 1989).

Sheep wool differs from synthetic fibers in its characteristics by strength, elasticity, ductility, elasticity, and similar physical properties. Sheep's wool has long been popular in alternative physiotherapy based on anti-inflammatory, tonic and analgesic effects. For this reason, people with weakened immune systems or certain diseases are advised to use clothes made of natural wool, cover and pillow with a non-synthetic sheep's skin blanket. It is also known in modern medicine that walking barefoot on a woolen carpet at home can lead to prevention of several diseases (Dzhetigenov \& Nurgaziev, 1989).

The electrostatic field created by wiping wool fibers has a positive effect on the body. This contributes to improving well-being, elimination of fatigue, joint diseases, minimization of pain with arthritis, radiculitis and normalization of the central nervous system or restoration of blood pressure.

Sheep's wool produces a significant amount of animal wax lanolin. Lanolin has anti-allergic, anti-tumor and anti-inflammatory properties and helps to heal wounds, restore the movement of joints and damaged tissues, eliminate inflammatory processes. Lanolin is used in the manufacture of oils, gadermine care products and so on (El-Sayed et al., 2018).

Kyrgyz people raised sheep wool that is soft and pleasant to the touch, they usually wore woolen clothes in cool weather. For joint diseases, it is recommended to wrap the joints with sheep's wool. This will help to improve the situation and eliminate the painful feelings. People with thyroid pathology are advised to use the following remedy: roll a piece of wool in salt, apply it to the area of the gland and tie it. The procedure is performed in the evening until duration of the therapeutic course was restored. The compress should always be fresh and sheep's skin helps children get rid of flatulence and meteorism by sticking a small piece of sheep's skin on the abdomen. For the treatment of postpartum 
encephalopathy, characterized by increased intracranial pressure, severe headache, it is recommended to tie child's head with a sheep's wool ribbon. Also, to make a small mattress and put a newborn baby on it. It warms the baby, lowers blood pressure, and improves tissue microcirculation.

As for the medicinal properties of sheep's wool, in traditional Kyrgyz medicine, the physical properties of animal hair are well known. For example, people have always been close to wool. It has positive energy and cures many diseases. In ancient times, a sheep's wool was placed on a sore spot when a person had a toothache, headache, or backache. They were able to get rid of joint diseases with wool yarn by tiding piece of wool to patient's wrist or ankle. Life experience has shown that wool has hemostatic properties. Even babies born in the past wrapped in sheep's wool (Nookat region field materials, 2020).

Natural sheep's wool is a cure for many diseases. For example, woolen shoes (felt boots, socks, felt shoes) improve blood circulation (Belleblog, 2017), perform the function of micro massage and normalize blood pressure not only on the skin, but throughout the body; felt boots, felt shoes, and simply knitted woolen socks noticeably improves blood circulation, dilates blood vessels and reduces blood pressure in hypertension (Podulova, 2012). Wool fibers, adhering to the skin, thereby perform a micro massage. The hair villi gently massage nerve endings on the human body at the capillary level, which improves blood circulation and normalizes blood pressure throughout the body.

Lamb's wool is including lanolin (animal wax), due to its unique properties lanoline, ceramide, peptone, and keratin have been proposed for wool to be utilized in pharmacotherapy cosmetics, and medical treatment (Allafi et al., 2020). Lanolin is a natural antiseptic, which can be used in cosmetics creams for skin treatment, have a beneficial effect on the joints and spine, relieve muscle tension, and improve blood circulation with respiratory function (Woolsoft, 2021). Cutted sheep or goat wool should be sorted depending on wool color and texture (Figure 1).

The fibrous structure of sheep's wool is complex and has many air pores. Due to this, it has a high level of thermal insulation. Wool is the fibrous coating from sheep (Figure 2), is the most important animal fiber used by the textile industry (Rippon et al., 2016). Wool absorbs up to $40 \%$ moisture and stays dry. Wool products are recommended for people suffering from the following diseases: arthrosis, arthritis, rheumatism, osteochondrosis, orthopedic diseases, allergies, muscle aches, asthma and poor blood supply. Sheep's wool is effective against pneumonia. In this case, a "warmer" made of sheep's wool is placed on the naked body and worn day and night. This method is effective in combating inflammatory foci in the lungs. Sheep's wool also helps with diseases such as otitis, sinusitis, and submandibular lymphadenitis. Pieces of sheep's wool were applied to the ear, maxillary sinus, and lymph nodes under the jaw or neck to reduce inflammation and pain. Any disease destroys the energy potential of the human body. Wool, on the other hand, balances and normalizes it. 


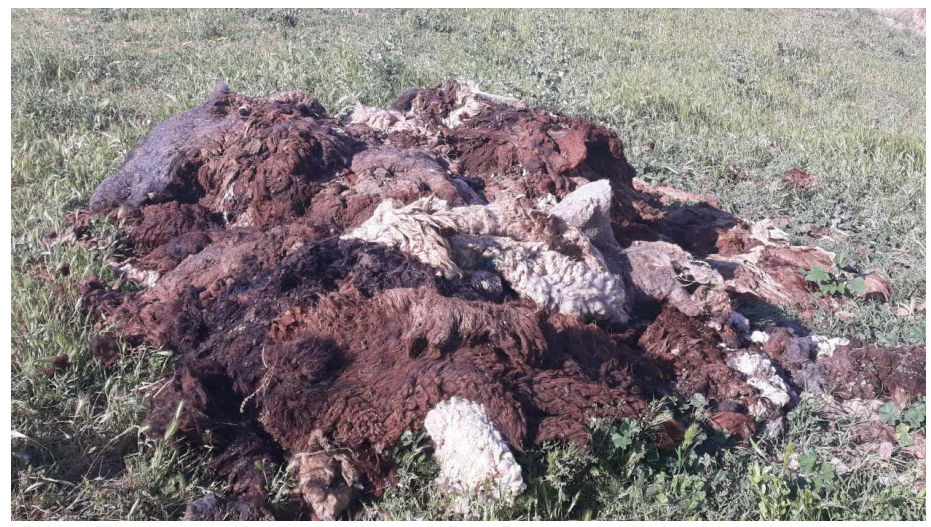

Figure 1. The process of sorting wool according to texture and color after cutting.

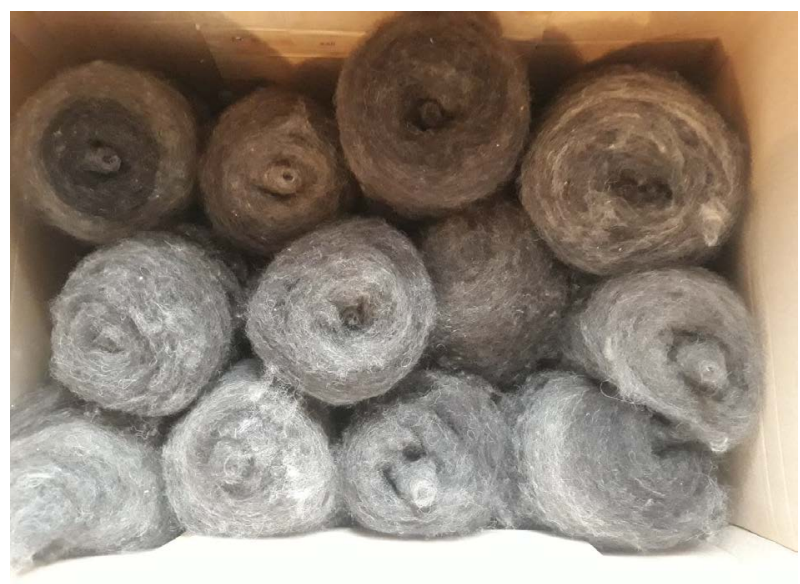

Figure 2. Washed, straightened and rolled wool after cutting.

The Kyrgyz people are well aware that sheep's wool also has anticoagulant properties. When a sheep's wool is burned, it releases a substance that has the property of thickening the blood. Thus, in the late nineteenth and early twentieth centuries, Kyrgyz traditional medicine was limited to natural medicines and existed in harmony with nature, closely related to the Kyrgyz people's philosophical worldview and ethical concepts.

\section{Conclusion}

Sheep's wool possesses anticoagulant properties; Kyrgyz people put wool in a bleeding place and press it on the place where blood bleeds, after that bleeding can stop quickly. This is because when a sheep's wool is burned, it releases a substance that has the property of thickening the blood vessels. Kyrgyz people used sheep's wool to stop bleeding in the late nineteenth and early twentieth centuries because natural sheep's wool is a cure for many diseases. Sheep's wool is different from synthetic fibers by strength, elasticity, ductility, elasticity characteristics and similar physical properties. Lamb wool has important properties because lanolin, ceramide, peptone, and keratin had been proposed for applications in cosmetics, medical treatment and pharmacotherapy. In ancient times, 
people were able to get rid of joint diseases with wool yarn by tiding piece of wool to patient's wrist or ankle. Life experience has shown that wool has hemostatic properties.

\section{Conflicts of Interest}

The authors declare no conflicts of interest regarding the publication of this paper.

\section{References}

Allafi, F., Hossain, Md. S., Lalung, J., Shaah, M., Salehabadi, A., Ahmad, M. I., \& Shadi, A. (2020). Advancements in Applications of Natural Wool Fiber: Review. Journal of Natural Fibers, 1-16. https://doi.org/10.1080/15440478.2020.1745128

Belleblog (2017). Sheep's Wool. Healing Properties. https://bellehome.ru/journal/ovechya-sherst

Ciani, E., Lasagna, E., D’Andrea, M., Alloggio, I., Marroni, F., Ceccobelli, S., Delgado Bermejo, J. V., Sarti, F. M., Kijas, J., Lenstra, J. A., Pilla, F., \& The International Sheep Genomics Consortium (2015). Merino and Merino-Derived Sheep Breeds: A Genome-Wide Intercontinental Study. Genetics Selection Evolution, 47, 64.

https://doi.org/10.1186/s12711-015-0139-z

Deniskova, T., Dotsev, A., Lushihina, E., Shakhin, A., Kunz, E., Medugorac, I., Reyer, H., Wimmers, K., Khayatzadeh, N., Sölkner, J., Sermyagin, A., Zhunushev, A., Brem, G., \& Zinovieva, N. (2019). Population Structure and Genetic Diversity of Sheep Breeds in the Kyrgyzstan. Frontiers in Genetics, 10, 1311. https://doi.org/10.3389/fgene.2019.01311

Dzhetigenov, A., \& Nurgaziev, C. (1989). Types of Sheep Products. Basics of Sheep Breeding (295 p.). Frunze: School.

El-Sayed, H. E.-D. Z., Mowafi, S., El-Kheir, A. A., \& El-Khatib, E. M. (2018). A Comprehensive Critique on Wool Grease Extraction, Properties and Applications. Egyptian Journal of Chemistry, 61, 1151-1159. https://doi.org/10.21608/ejchem.2018.4214.1372

Farrington, J. (2005). De-Development in Eastern Kyrgyzstan and Persistence of Semi-Nomadic Livestock Herding. Nomadic Peoples, 9, 171-197.

https://doi.org/10.3167/082279405781826191

Giles, J. (2009). Brief History of Sheep and Wool. https://www.fibre2fashion.com/industry-article/4295/brief-history-of-sheep-and-wool

Kristoffersen, A. E., Stub, T., Melhus, M., \& Broderstad, A. R. (2017). Prevalence and Associations for Use of a Traditional Medicine Provider in the SAMINOR 1 Survey: A Population-Based Study on Health and Living Conditions in Regions with Sami and Norwegian Populations. BMC Complementary Medicine and Therapies, 17, 530. https://doi.org/10.1186/s12906-017-2037-0

Large Soviet Encyclopedia (2021). Comparative-Historical Method. https://www.booksite.ru/fulltext/1/001/008/105/491.htm

Lushikhin, M. N. (1964). Fine Wool Sheep Breeding in Kyrgyzstan (228 p.). Frunze: Kyrgyzstan State Publishing House.

McMahon, A. (2020). Early Urbanism in Northern Mesopotamia. Journal of Archaeological Research, 28, 289-337. https://doi.org/10.1007/s10814-019-09136-7

Podulova, I. (2012). Useful Properties of Sheep's Wool Products.

Ratnapalan, L. (2008). E. B. Tylor and the Problem of Primitive Culture. History and 
Anthropology, 19, 131-142. https://doi.org/10.1080/02757200802320934

Rippon, J. A., Christoe, J. R., Denning, R. J., Evans, D. J., Huson, M. G., Lamb, P. R., Millington, K. R., \& Pierlot, A. P. (2016). Wool: Structure, Properties, and Processing. In Encyclopedia of Polymer Science and Technology (402 p). Hoboken, NJ: John Wiley \& Sons. https://doi.org/10.1002/0471440264.pst402.pub2

Sabatini, S., Bergerbrant, S., Brandt, L. Ø., Margaryan, A., \& Allentoft, M. E. (2019). Approaching Sheep Herds Origins and the Emergence of the Wool Economy in Continental Europe during the Bronze Age. Archaeological and Anthropological Sciences, 11, 4909-4925. https://doi.org/10.1007/s12520-019-00856-x

Satybaldieva, C. T. (2009). Traditional Kyrgyz Embroidery in the Second Half of the $X I X-$ The Beginning of the XX Century (155 p.). Osh: Maximum.

Satybaldieva, C., Tashalieva, M., Eshnazarova, Z., Tagaibekova, A., Satybaldieva, A., Tashalieva, Z., \& Abdullaeva, Z. (2021). Traditional Kyrgyz Carpet Weaving Process and Semantics of Related Customs. Advances in Anthropology, 11, 68-75. https://doi.org/10.4236/aa.2021.111006

Sidortsev, V. I., Belik, N. I., \& Serdyukov, I. G. (2010). Wool Application with the Basics of Quality Management and Marketing of Raw Wool(287 p.). Stavropol: Argus.

Woolsoft (2021). Lanolin Properties. http://woolsoft.ru/lanolin

Yuan, H., Ma, Q., Ye, L., \& Piao, G. (2016). The Traditional Medicine and Modern Medicine from Natural Products. Molecules (Basel, Switzerland), 21, 559.

https://doi.org/10.3390/molecules21050559 